\title{
Effect of Aluminum Surface State on Laser Joining between 1050 Aluminum Sheet and Polypropylene Resin Sheet Using Insert Materials*1
}

\author{
Makoto Hino $^{1}$, Yutaka Mitooka ${ }^{1}$, Koji Murakami ${ }^{1}$, Kazuto Urakami ${ }^{2}$, \\ Hiroyuki Nagase $^{3, * 2}$ and Teruto Kanadani ${ }^{3}$ \\ ${ }^{1}$ Industrial Technology Research Institute of Okayama Prefecture, Okayama 701-1296, Japan \\ ${ }^{2}$ Hayakawa Rubber Co., LTD., Hiroshima 721-8540, Japan \\ ${ }^{3}$ Faculty of Engineering, Okayama University of Science, Okayama 700-0005, Japan
}

Laser joining for different materials between 1050 aluminum alloy sheet of $1 \mathrm{~mm}$ thickness and polypropylene sheet of $2 \mathrm{~mm}$ thickness using a newly developed insert sheet was studied. The diode laser-irradiation to the polypropylene side was carried out in air. The effects of the aluminum surface state on the joining properties were examined. The joining strength increased with the increase in aluminum surface area except for the surface with the intense ruggedness. It was found that the chemical condition of aluminum surface treated with the acid or alkaline solution strongly affected the joining strength rather than the surface roughness. [doi:10.2320/matertrans.L-M2011804]

(Received September 30, 2010; Accepted February 2, 2011; Published April 13, 2011)

Keywords: laser joining, different material, insert material, diode laser, aluminum-plastics, elastomer

\section{Introduction}

Recently, aluminum alloys are increasingly being used to improve the fuel consumption of vehicles by reducing their weight along with their excellent workability and corrosion resistance. ${ }^{1)}$ Plastic materials are also increasingly being used for reduction in weight and cost because of their light weight and excellent formability. So, the importance of plastic joining technology has increased.

The new joining technology ${ }^{2)}$ between plastics of equal type by using a property of a laser beam around $1 \mu \mathrm{m}$ wavelength that could penetrate the plastic has been developed; thus this technology has mainly been used practically in the automobile industry because of its excellent productivity and joining quality compared to the general plastic welding technology such as hot plating, friction welding, ultrasonic welding. ${ }^{3)}$

On the other hand, joining a metal and a plastic is necessary and important from a manufacturing viewpoint. However, it is difficult to apply the foregoing laser plastic welding technology for this joining in terms of the bigger difference in physical properties between the joining materials. Such joining is generally performed using adhesive bonds or mechanical tools, such as bolts and rivets. These joining processes have problems in terms of environmental restriction on the emission of volatile organic compounds, the difficulties of mass production, and the high production cost. Therefore, another process strongly needs to be developed for joining metals and plastics. Recently, the development of a laser joining process for metal-plastic joints without adhesives or mechanical parts was attempted and then laser

\footnotetext{
${ }^{* 1}$ This Paper was Originally Published in Japanese in J. Japan Inst. Light Metals 60 (2010) 225-230

${ }^{* 2}$ Graduate Student, Okayama University of Science. Present address: Daisho Seiki, Ltd., Okayama 700-105, Japan
}

joining between a metal and plastic such as PET with a strong polarity. ${ }^{4)}$ We have reported that laser joining between metals and plastics became possible using a newly developed insert sheet in which the difference in physical properties between the joining materials has been reduced. ${ }^{5,6)}$ The strong joining between nonpolar plastics such as PP and aluminum, which combination should not be joined together, could be achieved using an insert sheet with a polarity due to a carboxyl group, ${ }^{7)}$ and we indicated that the surface state of an aluminum substrate remarkably affected the joining strength. However, the details are not clear at present. In addition, the surface shape well-known in the anchor effect greatly influences the adhesive property.

In this study, regarding laser joining between a 1050 aluminum sheet and a polypropylene resin sheet with a newly developed insert sheet, the effects of surface shape and chemical state of the 1050 aluminum sheet due to surface treatment such as alkaline dipping or acid dipping on the joining properties were examined.

\section{Experimental Procedure}

A 1050 aluminum sheet (hereafter described as "1050") $\left(30 \times 25 \times 1^{\mathrm{t}} \mathrm{mm}\right)$, the chemical composition which is shown in Table 1, and a polypropylene sheet (Shin-Kobe Electric Machinery Co., Ltd., KOBE POLYSHEET, hereafter described as "PP") $\left(50 \times 25 \times 2^{\mathrm{t}} \mathrm{mm}\right)$ were used as the joining materials. Four different kinds of surface shapes were produced by the standard polishing shown in Table 2 on the joining surface of the 1050 substrates so as to clarify the effect of the 1050 surface shape on the joining strength. After each polishing, ultrasonic cleaning in acetone was carried out for $60 \mathrm{~s}$.

SEM observation and a 3D surface shape measurement (Zygo New View 5000) were conducted on each polished surface, and the arithmetic mean roughness (Ra) and surface 
Table 1 Chemical composition of 1050 aluminum alloy. (mass\%)

\begin{tabular}{lcccccccccc}
\hline Alloy & $\mathrm{Si}$ & $\mathrm{Fe}$ & $\mathrm{Cu}$ & $\mathrm{Mn}$ & $\mathrm{Mg}$ & $\mathrm{Cr}$ & $\mathrm{Zn}$ & $\mathrm{Ti}$ & $\begin{array}{c}\text { Others } \\
\text { total }\end{array}$ & $\mathrm{Al}$ \\
\hline A1050P & 0.24 & 0.37 & 0.02 & 0 & 0 & 0 & 0 & 0.03 & 0.01 & bal. \\
\hline
\end{tabular}

Table 2 Various polishing conditions for 1050 aluminum substrate.

\begin{tabular}{cccc}
\hline$\# 220$ & $\# 1200$ & $\# 4000$ & Mirror buffing \\
\hline Substrate & Substrate & Substrate & Substrate \\
$\downarrow$ & $\downarrow$ & $\downarrow$ & $\downarrow$ \\
$\# 220$ & $\# 220$ & $\# 220$ & $\# 220$ \\
& $\downarrow$ & $\downarrow$ & $\downarrow$ \\
& $\# 800$ & $\# 800$ & $\# 800$ \\
& $\downarrow$ & $\downarrow$ & $\downarrow$ \\
& $\# 1200$ & $\# 1200$ & $\# 1200$ \\
& $\downarrow$ & $\downarrow$ \\
& & $\# 4000$ & $\# 4000$ \\
& & $\downarrow$ \\
& & & Mirror buffing \\
\hline
\end{tabular}

Table 3 Chemical treatments for 1050 aluminum substrate after mirror buffing.

\begin{tabular}{ccc}
\hline Alkaline dipping & Acid dipping & Second alkaline dipping \\
\hline $\mathrm{Na}_{2} \mathrm{CO}_{3}\left(20 \mathrm{~kg} / \mathrm{m}^{3}\right)+$ & & \\
$\mathrm{Na}_{2} \mathrm{SiO}_{3}\left(10 \mathrm{~kg} / \mathrm{m}^{3}\right)$ & Alkaline dipping & Acid dipping \\
$(325 \mathrm{~K}-30 \mathrm{~s})$ & $\downarrow$ & $\downarrow$ \\
$\downarrow$ & Washing & Washing \\
Washing & $\downarrow$ & $\downarrow$ \\
& Nitric acid (60\%) & Alkaline dipping \\
& (Room temperature-5 s) & $\downarrow$ \\
& Washing & Washing
\end{tabular}

area (I Surf Area) were obtained. In addition, chemical treatments shown in Table 3 were done for a mirror surface by buffing in order to clarify the effect of the chemical state of the 1050 surface on the joining strength. After the chemical treatment, X-ray photoelectron spectroscopy (hereafter described as "XPS") analysis was conducted on each treated surface in order to examine the chemical state.

The insert sheet was placed between the joining materials, as illustrated schematically in Fig. 1, and laser joining was conducted under the conditions shown in Table 4.

In our research, the irradiation involved an $808 \mathrm{~nm}$ wavelength line beam from a diode laser (Laser Line Co., Ltd., LDF600-1000, Maximum output: $1 \mathrm{~kW}$ ). The styrene block copolymer (SBC) thermoplastic elastomer fabricated into a sheet $50 \mu \mathrm{m}$ in thickness was used as the insert material. The thermoplastic elastomer consists of a flexible component (soft phase) and a restraining one (hard phase). Because the hard phase prevents plastic deformation, the elasticity of the thermoplastic elastomer is comparable to those of vulcanized rubbers. The elastomer once plasticized by heating can be hardened reversibly by cooling, and its strength is thus preserved even without reinforcement.

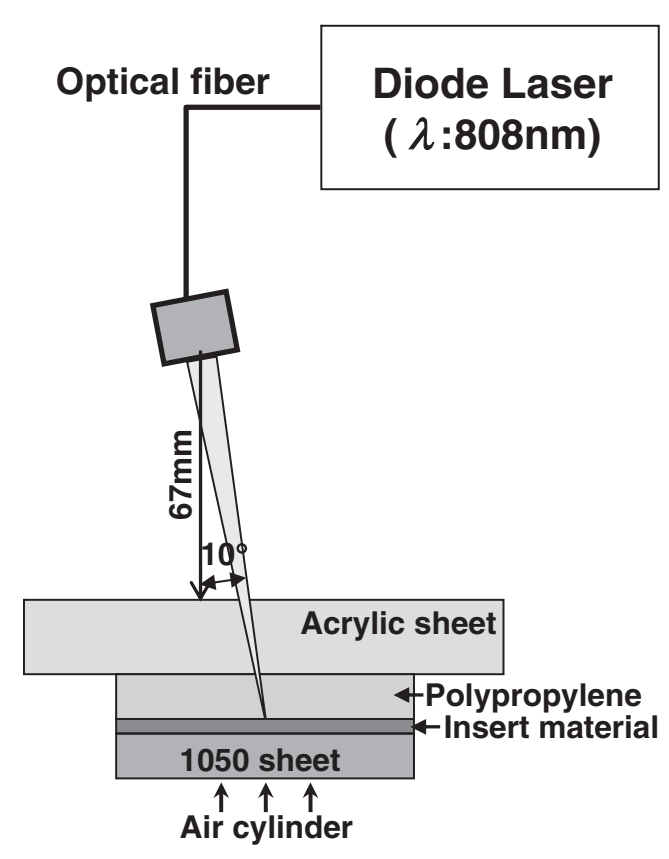

Fig. 1 Schematic drawing of experimental set-up of laser joining.

Table 4 Experimental conditions of laser joining.

\begin{tabular}{cc}
\hline Wavelength & $808 \mathrm{~nm}$ \\
Focusing distance & $100 \mathrm{~mm}$ \\
Spot diameter & $600 \mu \mathrm{m}$ \\
Defocusing distance & $12 \mathrm{~mm}$ \\
Exposure mode & $\mathrm{CW}$ \\
Exposure angle & $80^{\circ}$ for the joining material \\
Laser power & $200 \mathrm{~W}$ \\
Joining Speed & $5 \mathrm{~mm} / \mathrm{s}$ \\
\hline
\end{tabular}

In this study, polarity was given by a carboxyl group for these insert materials in order to improve the joining ability with 1050 , and 1 mass $\%$ of a laser absorption pigment (absorption ratio for $808 \mathrm{~nm}$ wavelength: 95\%) was added into these insert materials in order to improve the absorption of the laser beam. ${ }^{6}$

After the laser irradiation, surface and cross-sectional observations at the joining area were undertaken, and the joining strength was measured by a shearing test. After the shearing test, an observation and an element mapping analysis of the peeling plane were carried out by field emission electron probe microanalysis (hereafter described as "FE-EPMA") in order to reveal the peeling mode.

\section{Results and Discussion}

\subsection{Effects of surface shape on the joining strength}

Figure 2 shows the secondary electron images and the three-dimensional surface shapes obtained by a non-contact optical metrology system for 3D surface measurements of the various surfaces polished as shown in Table 2 for the 1050 substrate. Many polishing scratches are observed on the surface polished with a \#220 polishing paper, and then those surfaces become smooth in turn as the 1050 surface was 

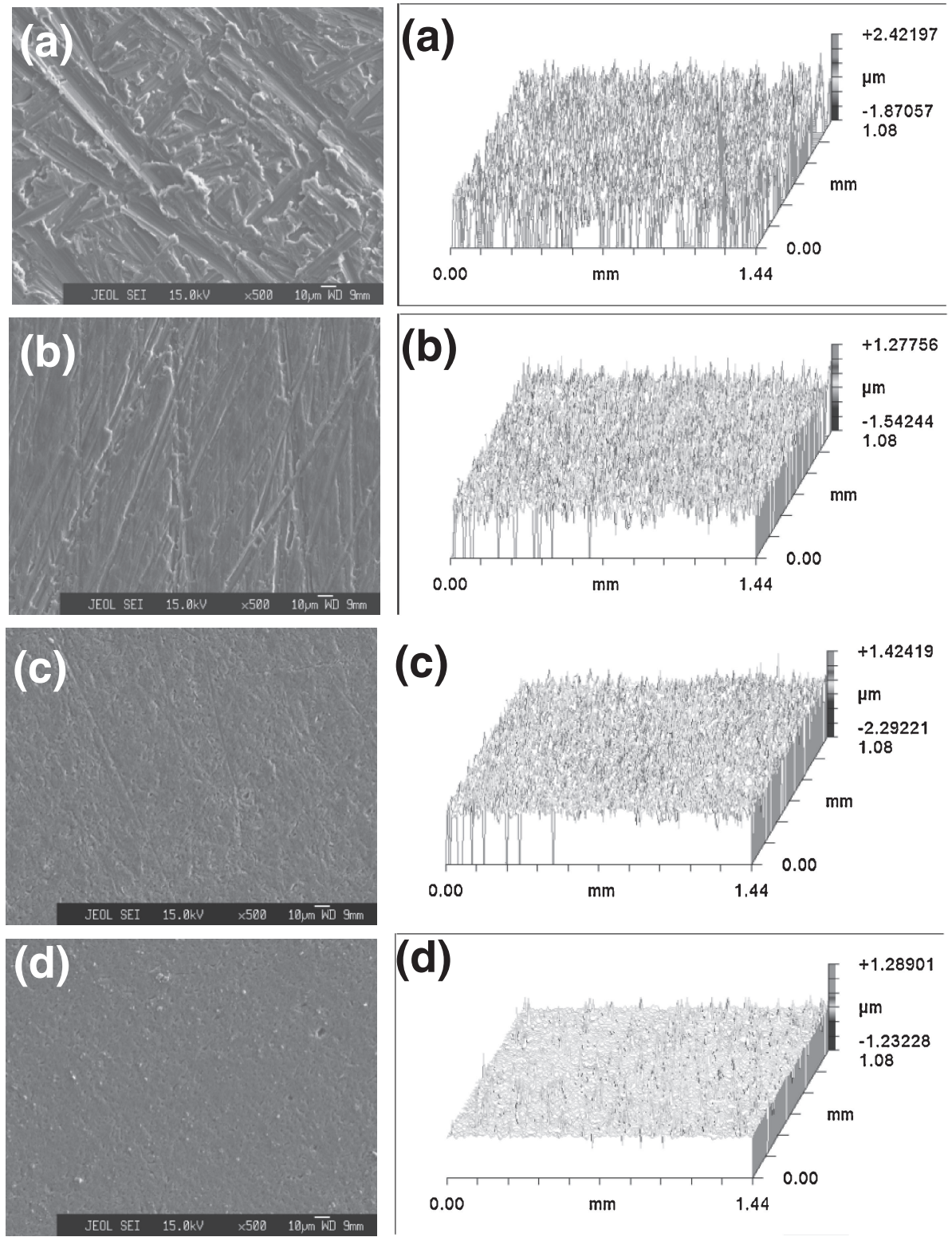

$50 \mu \mathrm{m}$

Fig. 2 Secondary electron images and surface morphology of specimens showing various polished surface on 1050 aluminum substrate. (a) \#220, (b) \#1200, (c) \#4000, (d) Mirror buffing.

Table 5 Surface roughness (Ra) of various polishing for 1050 aluminum substrate.

\begin{tabular}{ccccc}
\hline & $\# 220$ & $\# 1200$ & $\# 4000$ & Mirror buffing \\
\hline $\operatorname{Ra}(\mu \mathrm{m})$ & 0.420 & 0.192 & 0.145 & 0.063 \\
\hline
\end{tabular}

polished with a smoother polishing paper. The scratches were completely removed, and the surface became a mirror finish by final buffing.

Table 5 shows the surface roughness $(\mathrm{Ra})$ of various polished surfaces obtained by a non-contact optical metrology system for 3D surface measurements. The surface roughness $(\mathrm{Ra})$ decreased as the 1050 surface was polished by a smoother polishing paper, so the polished surface roughness after buffing was $0.063 \mu \mathrm{m} \mathrm{Ra}$.
The joining strength was measured by a shearing test on the laser-irradiated specimens with four different kinds of surface roughness ( $\mathrm{Ra}$ ) with an insert sheet. Figure 3 shows the relationships between the surface roughness ( $\mathrm{Ra}$ ) shown in Table 2 and the joining strength. The shear strength changed according to the value of the surface roughness $\mathrm{Ra}$; however, a correlation between the surface roughness and shear strength was not obtained. In particular, the shear strength of the \#220 polished specimen whose surface is the roughest ( $\mathrm{Ra}$ value: $0.420 \mu \mathrm{m}$ ) is lower than that of the smoother surface whose $\mathrm{Ra}$ value is $0.1445 \mu \mathrm{m}$, polished by \#4000 polishing paper. These results indicate that another controlling factor on the joining strength exists in addition to the surface shape.

Figure 4 shows the relationships between surface area (I Surf Area) obtained by a non-contact optical metrology 


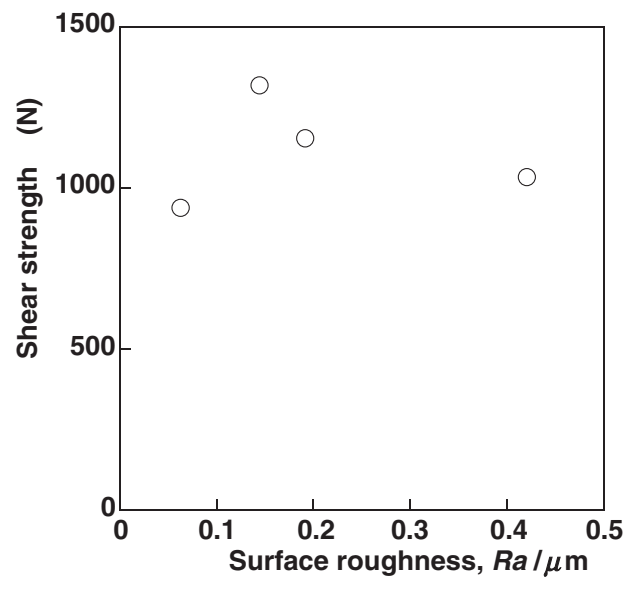

Fig. 3 Relationships between surface roughness and shear strength.

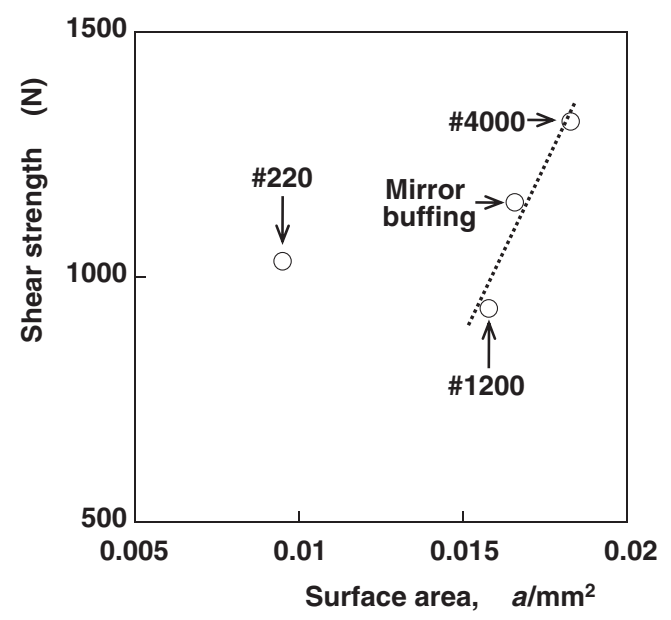

Fig. 4 Relationships between surface area and shear strength.

system for 3D surface measurements and shear strength. Further, the reason why the value of the surface area polished by \#220 polishing paper was the smallest among all specimens regardless of the fact that the biggest surface roughness value may be due to a data defect rate of $58 \%$ because of the great unevenness of the surface in comparison with these values being under $1 \%$ for other specimens. Except for the specimen polished with \#220 polishing paper, the shear strength was proportional to the surface area. It was found that the surface area was an important factor in the joining strength using this process. The factor in which the shear strength does not correlate with surface area is described later.

\subsection{Characteristics of the joining interface}

Figure 5 shows the cross-sectional backscattered electron images of a laser joined specimen with various polishing conditions except for the specimen polished with \#220 polishing paper. Joining defects such as bubbles and nonjoined areas were not observed at the joining interface between the PP and the insert materials. A sound joining interface has been found to be formed in all specimens. The joining defects were also not observed at the joining interface between the 1050 and the insert materials.

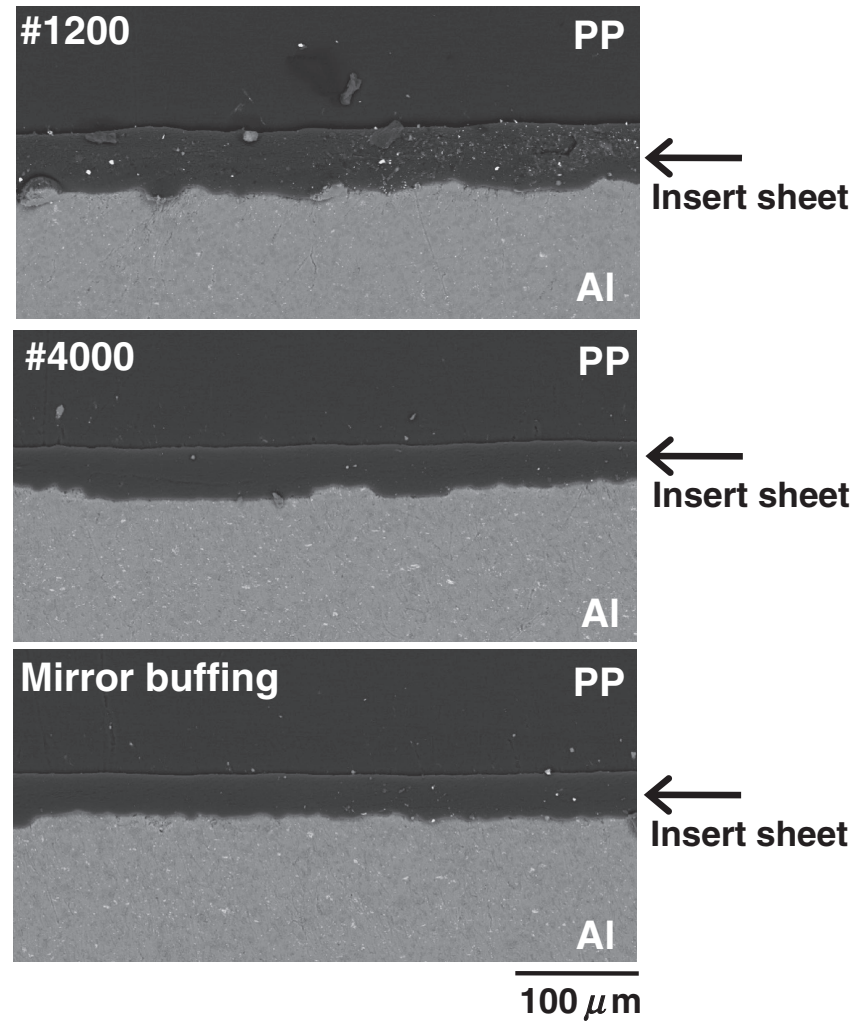

Fig. 5 Cross-sectional backscattered electron images of laser joining specimen with various polishing conditions.

On the other hand, there was no correlation between surface area and shear strength at the specimen polished with \#220 polishing paper in Fig. 4. The interface between the 1050 and insert materials was observed in detail in order to clarify this factor. Further, the specimens for cross-sectional observation were prepared by a cross-section polisher. Figure 6 shows the results of the specimen polished with \#220 and buffing. On the \#220 specimen whose surface was the roughest, the insert material was not perfectly filled (Fig. 6(a) broken line area) and a bubble was observed at the concavity. At the joining interface of the other specimens, nonjoined areas and bubbles as joining defects at the \#220 specimen were not observed. Because the joining strength of the \#220 specimen is lower due to joining defects such as nonjoined areas and a bubble at the concavity, the surface area does not correlate with joining strength.

Based on these results, the increase in the surface area of the aluminum joining plane has made it possible to increase the joining strength; however, the joining strength of a rough surface such as the \#220 specimen was lowered due to the nonfilling of the insert material into the concavity. In this way, the surface roughening for the purpose of the improvement in joining strength reversely causes a decrease in the joining strength due to the generation of joining defects. Therefore, the selection of an optimum surface shape is important in order to improve the joining strength of this process.

As the peeling planes after a shearing test were examined by visual observation, the peeling of each specimen was generated between a 1050 and PP but no peeling was observed between a PP and the insert materials. These results 

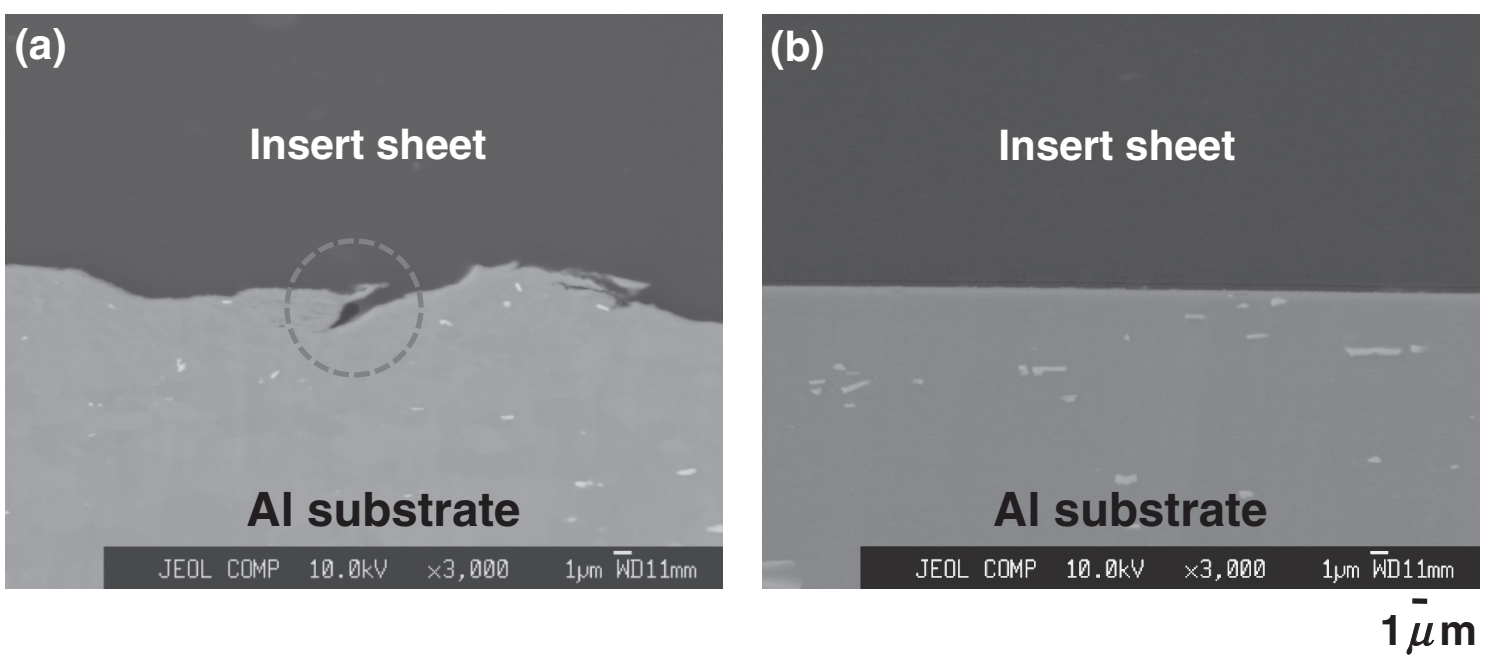

Fig. 6 Cross-sectional backscattered electron images of laser joining specimens. (a) \#220 polishing (b) mirror buffing.

Table 6 Surface roughness ( $\mathrm{Ra}$ ) and surface area (I Surf area) of various chemical treatments for mirror buffing substrate.

\begin{tabular}{ccccc}
\hline & $\begin{array}{c}\text { No } \\
\text { treatment }\end{array}$ & $\begin{array}{c}\text { Alkaline } \\
\text { dipping }\end{array}$ & $\begin{array}{c}\text { Acid } \\
\text { dipping }\end{array}$ & $\begin{array}{c}\text { Second alkaline } \\
\text { dipping }\end{array}$ \\
\hline $\begin{array}{c}\text { Surface roughness, Ra } \\
(\mu \mathrm{m})\end{array}$ & 0.063 & 0.219 & 0.214 & 0.207 \\
\hline $\begin{array}{c}\text { Surface area } \\
\left(\mathrm{mm}^{2}\right)\end{array}$ & 0.016 & 1.548 & 1.540 & 1.540 \\
\hline
\end{tabular}

are attributable to the compatibility ${ }^{8)}$ between the insert material consisting of a styrene block copolymer thermoplastic elastomer and PP. That is to say, at the joining interface between the insert materials and PP, both melted and then mingled with each other after laser irradiation due to the compatibility described above. ${ }^{9)}$ However, only the insert material melts at the joining interface between the insert materials and aluminum.

As a result of the elemental analysis by FE-EPMA for the 1050 surface where the insert materials were exfoliated, the carbon which originated from the insert material was detected from the peeling plane of each specimen. These results indicate that part of the insert material has caused the cohesive fracture, and so a bond, whose details are unknown, between the aluminum and the insert material seems to have been generated. Therefore, a firm joint in which the PP deforms plastically is obtained in this process. ${ }^{7)}$

\subsection{Effects of surface state due to the chemical treat- ment on joining strength}

Table 6 shows the surface roughness ( $\mathrm{Ra})$ and surface area (I Surf Area) of the specimens with chemical treatment shown in Table 3 for the 1050 with mirror buffing. The surface roughness after mirror buffing was Ra $0.063 \mu \mathrm{m}$, and so the surface was extremely smooth. On the other hand, the surface roughness $(\mathrm{Ra})$ increased with each chemical treatment, and the surface then became rougher; however, there was no significant difference in the surface roughness (Ra) and surface area (I Surf Area) with each chemical treatment. Therefore, an aluminum surface is etched in the first alkali
Table 7 Shear strength of various chemical treatments for 1050 aluminum substrate.

\begin{tabular}{ccccc}
\hline & $\begin{array}{c}\text { No } \\
\text { treatment }\end{array}$ & $\begin{array}{c}\text { Alkaline } \\
\text { dipping }\end{array}$ & $\begin{array}{c}\text { Acid } \\
\text { dipping }\end{array}$ & $\begin{array}{c}\text { Second alkaline } \\
\text { dipping }\end{array}$ \\
\hline $\begin{array}{c}\text { Shear strength } \\
(\mathrm{N})\end{array}$ & 936.7 & 1023.0 & 1122.3 & 847.7 \\
\hline
\end{tabular}

treatment, but that surface is hardly etched in the next chemical treatment such as the acid treatment or the second alkali treatment. Thus, in spite of the same alkali treatment for the buffing or acid treatment, the etching effect is remarkably different. This result demonstrates that the state of the oxide film which is formed after the buffing or acid treatment is different.

Table 7 shows the shear strength of the specimen after each chemical treatment. The shear strength with the first alkali treatment was improved in comparison with that of the buffing of a surface that was not first alkali treated. The shear strength with the next acid treatment then improved further than that with the first alkali treatment. However, the shear strength with the second alkali treatment was lowered further than that of the buffed specimen. In spite of the fact that there was little difference in the surface shape with each chemical treatment based on the results shown in Table 6, the shear strength after each chemical treatment was different. These results indicate that the chemical state of the surface aside from the surface shape seems to affect the joining strength in this process. In addition, the shear strength due to chemical treatment also showed a tendency to be equal to that of the foregoing specimen with mirror buffing except for the \#220 specimen with a nonjoined area depending on the extensive surface unevenness.

Figure 7 shows the XPS Al 3p1/2 narrow spectra at the surface with buffing and for each treated surface. The peaks of the metal and the oxidation state were present for all specimens, the proportion of the peak of the metal state and oxide state changing with each treatment. This result suggests that the chemical state at the outermost surface varies with each chemical treatment. 


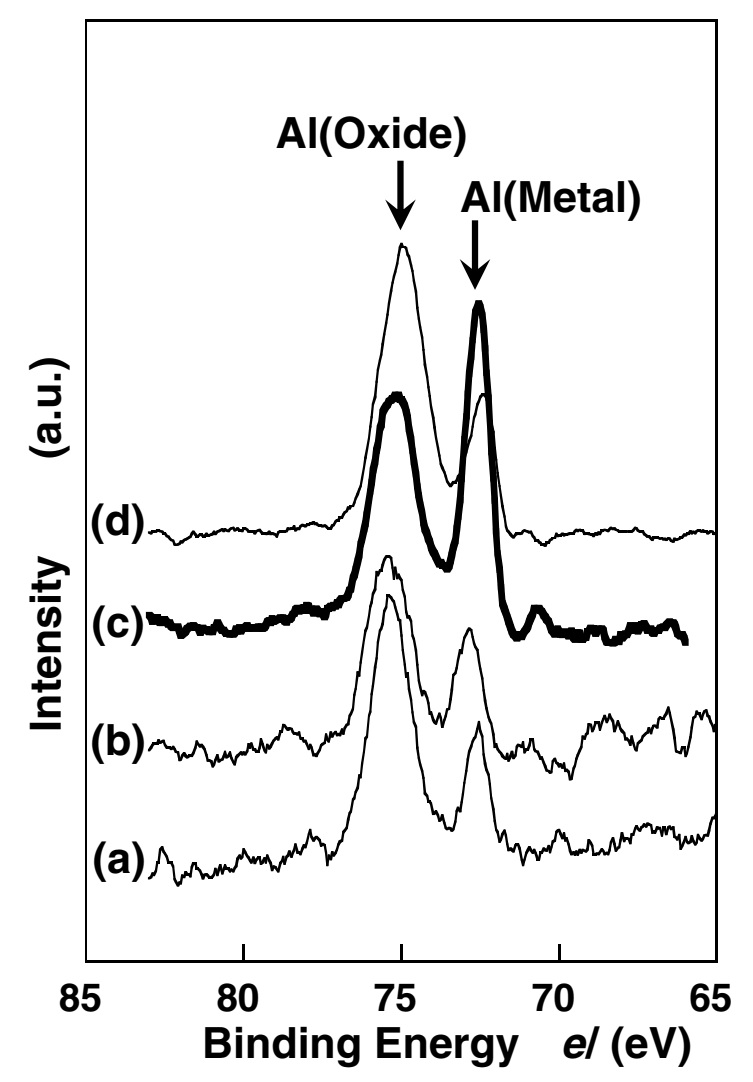

Fig. 7 XPS A13p1/2 narrow spectra of aluminum substrates after various chemical treatments. (a) No treatment, (b) Alkaline dipping, (c) Acid dipping, (d) Second alkaline dipping.

Table 8 Composition ratio of $\mathrm{Al}$ (Metal) and $\mathrm{Al}$ (Oxide) from $\mathrm{Al} 3 \mathrm{p} 1 / 2$ spectra.

\begin{tabular}{ccccc}
\hline & $\begin{array}{c}\text { No } \\
\text { treatment }\end{array}$ & $\begin{array}{c}\text { Alkaline } \\
\text { dipping }\end{array}$ & $\begin{array}{c}\text { Acid } \\
\text { dipping }\end{array}$ & $\begin{array}{c}\text { Second alkaline } \\
\text { dipping }\end{array}$ \\
\hline $\begin{array}{c}\mathrm{Al} \text { (Metal) } \\
\text { (at\%) }\end{array}$ & 25.8 & 27.3 & 45.7 & 18.6 \\
\hline $\begin{array}{c}\mathrm{Al} \text { (Oxide) } \\
\text { (at\%) }\end{array}$ & 74.2 & 72.7 & 54.3 & 81.4 \\
\hline
\end{tabular}

Table 8 shows the composition ratio of $\mathrm{Al}$ (Metal) and $\mathrm{Al}$ (Oxide) obtained from the results shown in Fig. 7. Regarding the ratio of the metallic state, that of the acid-treated specimen whose shear strength was the highest was the highest among all specimens. Conversely, that of the second alkali-treated specimen whose shear strength was the lowest was the lowest among all specimens. In this way, a correlation between the shear strength and the ratio of the metallic state was found.

In this study, the reactivity between the metal and the insert material allows improvement by giving the insert material polarity with a carboxyl group. Because the change in the chemical state of the aluminum surface by chemical treatment such as alkali or acid dipping significantly affects the reactivity with the insert materials, acid-base interaction $^{10)}$ is suspected to be responsible for the adhesion model between the 1050 and the insert materials. Degeneration of the insert material was produced by the $-\mathrm{NH}_{2}$ group which was the basic functional group in contrast with the $-\mathrm{COOH}$

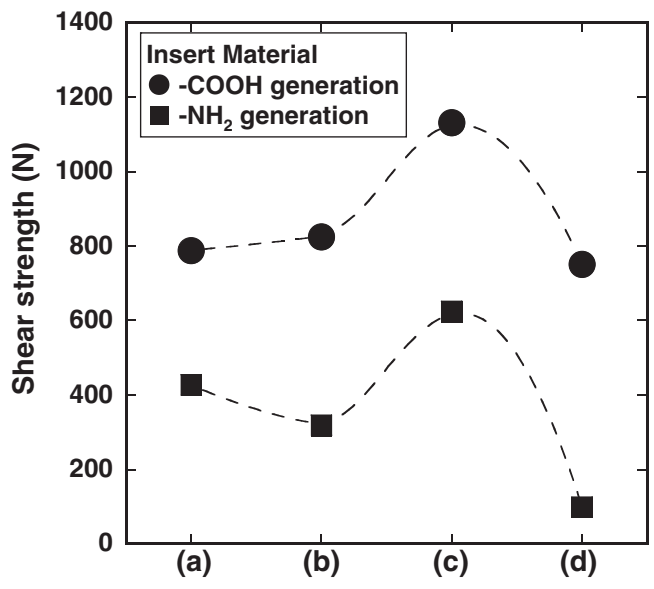

Fig. 8 Shear strength of various chemical treatments for 1050 aluminum substrate. (a) No treatment, (b) Alkaline dipping, (c) Acid dipping, (d) Second alkaline dipping.

group, and similar laser welding was then carried out; the shear strength was measured in order to clarify the acid-base interaction.

The rolled plane of the 1050 aluminum alloy sheet was used for the joining surface without buffing. These results are shown in Fig. 8. In comparison with the shear strength of the insert materials denatured by a $-\mathrm{COOH}$ group or an $-\mathrm{NH}_{2}$ group, because the shear strength after acid treatment is the highest though the absolute value is different, the shear strength due to each treatment tended to be similar. This result indicates that another joining mechanism exists in addition to the acid-base interaction.

In general, the adhesive bonds for metals having organic functional groups such as an $\mathrm{OH}$ radical, an $-\mathrm{NH}_{2}$ group, or a $-\mathrm{COOH}$ group in the molecule are firmly fixed on the metal surface by means of the interaction force based on the hydrogen bond between the hydroxyl groups on metal surface and the organic functional groups. ${ }^{10)}$ The results showing a similar tendency of the shear strength between the $-\mathrm{NH}_{2}$ group and the $-\mathrm{COOH}$ group as shown in Fig. 8 demonstrate that the hydrogen bond should be generated between the hydroxyl groups on the aluminum surface and the $-\mathrm{NH}_{2}$ group or $-\mathrm{COOH}$ group of the given insert materials. By the way, it was not possible to join 1050 and PP, because no reaction was generated between aluminum and the insert materials on using the insert materials without a denaturant. In addition, the difference in the oxidation state revealed by XPS analysis shown in Fig. 7 seems to affect the hydroxide which is adsorbed on the outermost surface, and the shear strength then changes.

Consequently, it was found that the chemical state of the surface was an important factor in the joining ability in this process. Because the surface shape also influences the joining ability, therefore control of both the surface shape and the chemical state of the surface are important in order to improve the joining ability. In particular, it is advantageous to apply this process to articles of a complicated shape by using a combination of fiber transmission and a robot for the laser joining. For the joining surface of these articles, the chemical treatment seems to be more efficient and easier to use than the mechanical treatment involving polishing, etc. 


\section{Conclusions}

The effects of a 1050 aluminum sheet having its surface shape and chemical state changed due to a surface treatment such as alkaline dipping or acid dipping on the joining strength between the 1050 aluminum sheet and the polypropylene resin sheet using the insert materials by a diode laser irradiation were examined, and we obtained following results.

(1) The increase in surface area of the aluminum in the joining plane was effective for the joining strength. However, it was found that as the surface became more roughened, the joining strength was lowered because of joining defects such as nonjoined areas and bubbles at the concavity. Therefore, the selection of the optimum surface shape is important in order to improve the joining strength in this process.

(2) The joining strength changed with a chemical treatment such as acid or alkaline dipping of the aluminum surface, and this tendency was similar for the insert materials denatured by a $-\mathrm{COOH}$ group or an $-\mathrm{NH}_{2}$ group. Therefore, a hydrogen bond is a controlling factor in the joining of aluminum and the insert materials compared to the acid-base interaction. At that time, the state of the hydroxyl group at the outermost surface depended on the oxidation state which seemed to affect the hydrogen bond, and the shear strength then changed.

\section{REFERENCES}

1) H. Horikawa: J. Jpn. Inst. Light Met. 58 (2008) 259-273 (in Japanese).

2) K. Mikame: J. Jpn. Laser Proc. Soc. 14 (2007) 211-215 (in Japanese).

3) Ed. By T. Hasegawa: Laser-zyushi-yochaku-gizyutu-knowhowshu, (Gizyutu-zyoho-kyokai, 2009) p. 292 (in Japanese).

4) S. Katayama and Y. Kawahito: Smart Process. Technol. 2 (2008) 19-22.

5) Y. Mitooka, K. Nagata and M. Hino: Jpn. Patent Pending, 2006-177613 (2006).

6) Y. Mitooka, M. Hino and K. Urakami: J. Jpn. Laser Proc. Soc. 15 (2008) 186-190 (in Japanese).

7) M. Hino, Y. Mitooka, K. Urakami, J. Takada and T. Kanadani: J. Jpn. Inst. Light Met. 59 (2009) 236-240 (in Japanese).

8) T. Osawa: Secchaku-handbook, 4th, (Ed. by The Adhesion Soc. of Jpn., Nikkankogyo-shinbunsya, 2007) pp. 136-138 (in Japanese).

9) Y. Mitooka, M. Hino, K. Urakami and J. Takada: J. Jpn. Laser Proc. Soc. 16 (2009) 236-240 (in Japanese).

10) T. Ogawa: Secchaku-handbook, 4th, (Ed. by The Adhesion Soc. of Jpn., Nikkankogyo-shinbunsya, 2007) pp. 836-840 (in Japanese). 